\title{
Impact of Rural-Urban Migration Experience on Rice Farmers' Agricultural Machinery Expenditure: Evidence from China
}

\author{
Yiduo Sun ${ }^{1}$, Ruifa $\mathrm{Hu}^{2}$ and Chao Zhang ${ }^{3, * \mathbb{D}}$ \\ 1 Department of Chemistry, Capital Normal University, Beijing 100048, China; 6773@cnu.edu.cn \\ 2 School of Management and Economics, Beijing Institute of Technology, Beijing 100081, China; \\ ruifa@bit.edu.cn \\ 3 School of Humanities and Social Sciences, Beijing Institute of Technology, Beijing 102488, China \\ * Correspondence: zhangchao@bit.edu.cn
}

Citation: Sun, Y.; Hu, R.; Zhang, C. Impact of Rural-Urban Migration

Experience on Rice Farmers'

Agricultural Machinery Expenditure: Evidence from China. Agriculture 2021, 11, 764. https://doi.org/ 10.3390/agriculture11080764

Academic Editor:

Gioacchino Pappalardo

Received: 17 June 2021

Accepted: 10 August 2021

Published: 11 August 2021

Publisher's Note: MDPI stays neutral with regard to jurisdictional claims in published maps and institutional affiliations.

Copyright: (c) 2021 by the authors. Licensee MDPI, Basel, Switzerland. This article is an open access article distributed under the terms and conditions of the Creative Commons Attribution (CC BY) license (https:/ / creativecommons.org/licenses/by/ $4.0 /)$.

\begin{abstract}
In China, return migrants' rural-urban migration experience and its impact on agricultural production have attracted increasing attention. Using the random survey data of 1122 rice farmers from the Yangtze River Basin in 2016, this study utilizes the endogenous treatment-effect model to investigate the impact of rural-urban migration experience on farmers' agricultural machinery expenditure. The results demonstrate that return migrants with rural-urban migration experience account for $23.3 \%$ of the total sampled farmers. After addressing the endogeneity issue, rural-urban migration experience can increase rice farmers' agricultural machinery expenditure by $500-600$ yuan/ha. Meanwhile, the positive impact of rural-urban migration experience on agricultural machinery expenditure is also heterogeneous in terms of farmers' age and rice farm size. Based on the results, this study proposes assisting return migrants' engagement in agriculture, supporting agricultural mechanization for the aged farmers, and enhancing the coordination between agricultural mechanization and appropriately scaled agricultural operations.
\end{abstract}

Keywords: rural-urban migration; return migrants; rice production; agricultural mechanization

\section{Introduction}

Agricultural mechanization is the key basis for speeding up the modernization of agriculture and rural areas and promoting rural vitalization on all fronts in China. Since the reform and opening up, China has made substantial progress in promoting agricultural mechanization. The total agricultural machinery power has increased from 117.5 million kilowatts in 1978 to more than 1 billion kilowatts in 2019 [1]. Meanwhile, agricultural mechanization has also significantly increased agricultural productivity in China [2,3]. In general, a farmer may employ agricultural machinery to replace manual labor when the household labor endowment is given [4-6]. During the past four decades, one of the most typical characteristics of rural development in China has been the flow of rural labor force between rural and urban areas [7,8]. In fact, this is also an international phenomenon $[9,10]$. In rural China, the implementation of the household contract system, an individual household-based farming system changing from the collective system since the late 1970s, dramatically increased agricultural productivity and produced massive surplus labor force in the rural areas [11,12]. Meanwhile, the continuous development of non-agricultural industries in the urban areas formed a huge demand for labor force, which absorbed the surplus labor force from rural China [13,14]. However, an increasingly large number of rural-urban migrants has actively or passively returned to their hometown due to various reasons since the 1990s [7,8]. Compared with the non-migrants, the return migrants with rural-urban migration experience have many different characteristics, and thus, their engagement in agriculture may alter agricultural labor force structure and further influence agricultural production $[15,16]$. 
While rural-urban migration and its impact have attracted much attention, only a few studies analyze the impact of return migrants' rural-urban migration experience on agricultural production. For example, Zhao [7] finds that the return migrants are more willing to increase productive investment in agriculture than the non-migrants, and each return migrant in a household would accordingly increase the productive investment in agriculture by $128.2 \%$. Shi and Yang [17] find that the rural-urban migration experience of the return migrants in Hubei not only leads farmers to adopt more new agricultural technologies, but also improves their capability in agricultural production, both of which could increase agricultural production efficiency. Using survey data of 586 return migrants and 1707 non-migrants, Chen et al. [15] empirically analyze the impact of rural-urban migration experience on farmers' farm size and conclude that rural-urban migration experience could promote farmers to expand their farm size by $22 \%$. Zhang et al. [16] further examine the relationship between rural-urban migration experience on fertilizer use in rice production and illustrate that rural-urban migration experience can help farmers to reduce fertilizer use after accounting for the self-selectivity bias.

In fact, many scholars have analyzed the determinants of farmers' agricultural machinery expenditure. Jiao and Dong [3] point out that industrialization and urbanization have promoted agricultural mechanization in China, and the incentive policies (e.g., the subsidy for agricultural machinery and training on agricultural machinery operation) have also exerted greatly positive impacts on agricultural mechanization. From an individual perspective, the changes in relative prices of production factors may alter farmers' agricultural machinery expenditure. For example, Liu et al. [18] utilize the survey data collected in Hebei and Shandong to analyze the elasticity of substitution between labor and other production factors and find that the increase in labor wage has a significantly positive impact on the expenditure of large agricultural machinery. Wang et al. [5] conclude that the drop in relative prices between machinery service and labor would increase agricultural machinery expenditure using provincial-level panel data from 1984 to 2012. Similarly, Cai et al. [6] also find that the change in relative prices between production factors would significantly influence farmers' demand for agricultural machinery technologies using the farmer survey data in Henan, Hebei, and Shandong. Moreover, land characteristics are also important factors that influence agricultural machinery expenditure. Using the survey data in Anhui, Hubei, Hunan, Jiangxi, and Guangdong in 2015, Li et al. [19] find that the expansion of farm size would result in the increase in agricultural machinery expenditure, but poor land quality and irrigation infrastructure would reduce agricultural machinery expenditure. Yang et al. [20] examine the impact of land fragmentation on agricultural machinery expenditure using the survey data of 1133 farmers and find that a higher level of land fragmentation would reduce farmers' agricultural machinery expenditure through its barrier and structural effects. Wang et al. [21] also demonstrate that land fragmentation would apparently restrict agricultural machinery expenditure when there is a rapid increase in labor wage or shortage of labor force. Using the farmer survey data in Hubei in 2016 and propensity score matching method, Peng and Wu [22] point out that land rent-in would increase the degree of agricultural mechanization by $9.9 \%$, while land rent-out would decrease the degree of agricultural mechanization by $9.4 \%$. In addition, Fang et al. [23] analyze the impact of off-farm employment on the utilization of agricultural machinery using the data from 2011 to 2014 in China and find that off-farm employment could significantly promote agricultural machination. Using the survey data of 2704 farmers in nine provinces, $\mathrm{Hu}$ and $\mathrm{Mi}$ [24] find that a more instable land tenure would significantly discourage farmers to buy agricultural machinery service.

However, whether and how rural-urban migration experience influences agricultural production, especially agricultural machinery expenditure, remains unclear. In the context of promoting rural revitalization on all fronts and speeding up the modernization of agriculture and rural areas in China, return migrants' engagement in agriculture may influence agricultural production especially agricultural mechanization, and thus, it has important policy implications to examine the impact of rural-urban migration experience 
on agricultural machinery expenditure among farmers. Using the survey data covering 1122 rice farmers in four provinces in the Yangtze River Basin, this study employs the endogenous treatment-effect model to investigate the impact of rural-urban migration experience on agricultural machinery expenditure and its heterogeneity by accounting for the potential endogeneity issue. The rest of this study is organized as follows. Section 2 provides the theoretical framework of this study, which analyzes how rural-urban migration experience influences farmers' agricultural machinery expenditure. Second 3 describes the endogenous treatment-effect model and data. In Section 4, the main econometric results as well as robustness checks and heterogeneity analysis are reported and discussed. The concluding remarks are provided in Section 5.

\section{Theoretical Framework}

This section attempts to explore the mechanism through which rural-urban migration experience influences farmers' agricultural machinery expenditure in rice production. Agricultural machinery is a typical production factor in agriculture. Farmers' adoption of agricultural machinery is determined by not only the budget constraint, but also the relative change in their expected price of production factors [5,6]. In Figure 1, the horizontal axis $L$ denotes labor input, and the vertical axis $M$ denotes agricultural machinery expenditure. Each of the isocost lines $C_{1}-C_{4}$ describes all the combinations of labor input and agricultural machinery expenditure for a given total cost separately. Meanwhile, $I_{1}-I_{3}$ denote the isoquants describing all the efficient combinations of labor input and agricultural machinery expenditure that can produce a single level of output separately. Let $w$ and $r$ denote the expected wage and price of agricultural machinery, and thus, the slope of the isocost lines is equal to $-w / r$.
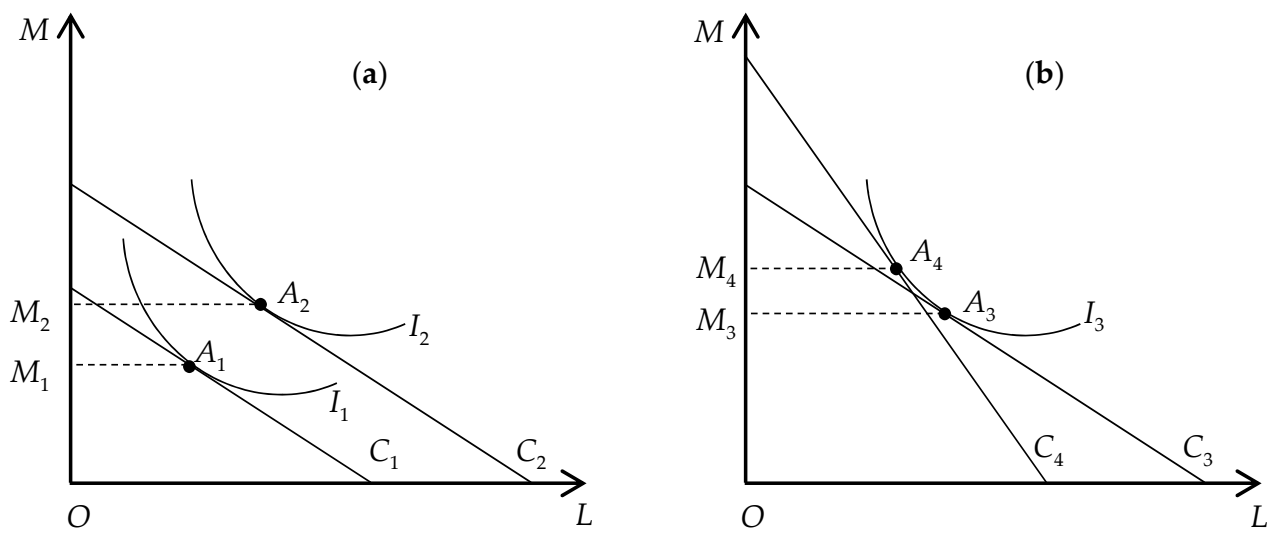

Figure 1. Influence mechanism of rural-urban migration experience on agricultural machinery expenditure. (a) describes the impact mechanism of rural-urban migration experience on agricultural machinery expenditure through increasing farmers' income and wealth; (b) describes the impact mechanism of rural-urban migration experience on agricultural machinery expenditure through increasing the expected price of labor relative to agricultural machinery.

Rural-urban migration experience can exert a positive impact on agricultural machinery expenditure through increasing farmers' income and wealth. As in Figure 1a, the isoquant $I_{1}$ is tangential to the isocost line $C_{1}$ at the point $A_{1}$ where the initial agricultural machinery expenditure is equal to $M_{1}$. Note that off-farm wage is always higher than labor wage in agriculture [25]. Thus, rural-urban migration experience can help return migrants to increase their income and wealth, which can further soften return migrants' budget constraint when they determine the inputs of production factors in agriculture. In this context, rural-urban migration experience may rightward shift the isocost lines from $C_{1}$ to $C_{2}$, resulting in the new isoquant $I_{2}$ being tangential to the isocost line $C_{2}$ at the point $A_{2}$. As a result, agricultural machinery expenditure moves from the initial $M_{1}$ to $M_{2}$. 
Rural-urban migration experience can increase the expected price of labor relative to agricultural machinery, which further promotes the substitute of agricultural machinery for labor. As Figure 1b, we assume that the isoquant $I_{3}$ is tangential to the isocost line $C_{3}$ at the point $A_{3}$ where the initial agricultural machinery expenditure is equal to $M_{3}$. Note that rural-urban migration experience can increase farmers' expected labor wage through three channels. First, rural-urban migration experience may promote the return migrants to form a relatively higher expected wage of labor in agriculture than the non-migrants, since off-farm wage is higher than the wage of labor in agriculture [25]. Second, rural-urban migration experience would promote farmers to broaden their horizons, improve their work capability, master advanced management philosophy, and cultivate their awareness of innovation [8,26-28], which could also promote the return migrants to increase the expected wage level. Third, the return migrants with rural-urban migration experience would to some extent have a larger propensity to participate in part-time off-farm work in their hometown even when they are engaged in agriculture. In this situation, those return migrants would spend more time on part-time off-farm work with higher expected wage, which would increase their agricultural machinery expenditure. When the price of agricultural machinery is given, the rise in expected labor wage would further lead the isocost lines to be steeper. With agricultural output held constant, the isocost lines would shift from $C_{3}$ to $C_{4}$, resulting in the shift of the intersection between isoquants and isocost line $I_{3}$ from the point $A_{3}$ to $A_{4}$. Accordingly, agricultural machinery expenditure also increases from $M_{3}$ to $M_{4}$.

Meanwhile, the positive impact of rural-urban migration experience on agricultural machinery expenditure among farmers may differ by farmers' age. On the one hand, physical strength and capability of agricultural labor force will deteriorate as they grow older [29], and thus, farmers may increase agricultural machinery expenditure as a substitute for manual labor. Thus, the impact of rural-urban migration experience on agricultural machinery expenditure may be enhanced as farmers grow older. On the other hand, the opportunity of off-farm work among farmers may be reduced as they grow older, and thus, they can spend more time on agricultural activities [30]. Meanwhile, the growth of farmers' age may also result in the decrease in farmers' expected labor wage [30], which lead the isocost lines to be steeper. Hence, the positive impact of rural-urban migration experience on agricultural machinery expenditure may be weakened as farmers' age grows.

As for different farm sizes, the impact of rural-urban migration experience on agricultural machinery expenditure may also be different. Note that farm size is a crucial factor influencing farmers' agricultural machinery expenditure [31]. Logically, the expansion of farm size would undoubtedly result in the increase in the demand for labor. However, a small-scale farmer may face the problem of labor shortage when she or he decides to expand farm size. In this context, an increase in agricultural machinery expenditure would be an effective substitute for manual labor [32]. Meanwhile, a small farm size may lead to a diminishing return on agricultural machinery that is detrimental to agricultural mechanization, while the expansion of farm size would have an effect of economies of scale, which could further promote farmers to increase their agricultural machinery expenditure [31,32].

As a summary, this study hypothesizes that rural-urban migration experience can increase agricultural machinery expenditure, and such a positive impact may differ by farmers' age and farm size.

\section{Materials and Methods}

\subsection{Endogenous Treatment-Effect Model}

This study aims to examine the impact of rural-urban migration experience on agricultural machinery expenditure among rice farmers. Hence, a multivariable regression model can be first developed as follows:

$$
Y_{i}=\alpha+\beta M_{i}+X_{i}^{\prime} \gamma+u_{i}
$$


where the subscript $i$ denotes the $i$-th farmer. $Y_{i}$ denotes agricultural machinery expenditure in rice production. $M_{i}$ is a dummy variable denoting farmers' rural-urban migration experience. $M_{i}$ is equal to one when a farmer is a return migrant, and zero when a farmer is a non-migrant. $\boldsymbol{X}_{i}$ denotes a vector of other factors that influence agricultural machinery expenditure. $\alpha, \beta$, and $\gamma$ are coefficients, and $u_{i}$ is a random error.

The ordinary least squares (OLS) method can produce an unbiased and consistent estimation of Equation (1) only when $M_{i}$ is randomly determined. However, farmers' out-migration and return may be jointly determined by many observable and unobservable factors that also exert an impact on farmers' agricultural production, which would result in a potential endogeneity issue arising from the self-selectivity of farmers' rural-urban migration experience [33]. It means that farmers' rural-urban migration experience is not a random variable, and thus, the OLS method cannot account for the endogeneity issue arising from the self-selectivity of rural-urban migration experience. In previous studies, the propensity score matching, difference-in-differences model, and endogenous switching regression model have been used to account for the endogeneity issue of a dummy variable, but all these methods have some drawbacks [34,35]. In contrast, the endogenous treatmenteffect model cannot only account for the endogeneity issue of a dummy variable due to observable and unobservable factors, but also provide both the average treatment effect and marginal effect of endogenous dummy variable on the dependent variable [36]. Hence, this study employs the endogenous treatment-effect model to account for the endogeneity issue of farmers' rural-urban migration experience.

In general, an endogenous treatment effect model consists of an outcome equation as Equation (1) and a selection equation with the endogenous dummy variable as the dependent variable [34]. Theoretically, whether a farmer is a return migrant is determined by the difference in expected utility of out-migration and non-migration. Let $U M_{i}$ denote the difference in expected utility. $M_{i}$ is equal to one when $U M_{i}$ is positive, and zero otherwise. It can be specified as:

$$
U M_{i}=\vartheta+Z_{i}^{\prime} \delta+v_{i}
$$

where $\boldsymbol{Z}_{i}$ can have the same variables included in $\boldsymbol{X}_{i}$. However, there should be at least one instrumental variable included in $Z_{i}$ but not included in $\boldsymbol{X}_{i}$. Meanwhile, the random errors of Equations (1) and (2) must follow a bivariate normal distribution as:

$$
\left(\begin{array}{c}
u_{i} \\
v_{i}
\end{array}\right) \sim N\left[\left(\begin{array}{l}
0 \\
0
\end{array}\right), \quad\left(\begin{array}{cc}
\sigma_{u}^{2} & \rho \sigma_{u} \\
\rho \sigma_{u} & 1
\end{array}\right)\right]
$$

where the variance of Equation (2), $\sigma_{u}^{2}$, is standardized to one. $\rho$ is the correlation coefficient between $u_{i}$ and $v_{i}$.

The conditional expectation of agricultural machinery expenditure among the return migrants can be expressed as:

$$
\begin{gathered}
E\left(Y_{i} \mid M_{i}=1\right)=\alpha+\beta+X_{i}^{\prime} \gamma+E\left(u_{i} \mid M_{i}=1\right) \\
E\left(Y_{i} \mid M_{i}=1\right)=\alpha+\beta+\boldsymbol{X}_{i}^{\prime} \gamma+E\left(u_{i} \mid v_{i}>-\vartheta-Z_{i}^{\prime} \delta\right) \\
E\left(Y_{i} \mid M_{i}=1\right)=\alpha+\beta+X_{i}^{\prime} \gamma+\rho \sigma_{u} \lambda\left(-\vartheta-Z_{i}^{\prime} \delta\right)
\end{gathered}
$$

Meanwhile, the conditional expectation of agricultural machinery expenditure among the non-migrants can be expressed as:

$$
\begin{gathered}
E\left(Y_{i} \mid M_{i}=0\right)=\alpha+\boldsymbol{X}_{i}^{\prime} \gamma+E\left(u_{i} \mid M_{i}=0\right) \\
E\left(Y_{i} \mid M_{i}=0\right)=\alpha+\boldsymbol{X}_{i}^{\prime} \gamma+E\left(u_{i} \mid v_{i} \leq-\vartheta-\boldsymbol{Z}_{i}^{\prime} \delta\right) \\
E\left(Y_{i} \mid M_{i}=0\right)=\alpha+\boldsymbol{X}_{i}^{\prime} \gamma-\rho \sigma_{u} \lambda\left(\vartheta+\mathbf{Z}_{i}^{\prime} \delta\right)
\end{gathered}
$$


where $\lambda(\bullet)$ denotes the inverse Mills ratio. Let $\varphi(\bullet)$ and $\Phi(\bullet)$ denote the standard normal probability density function and standard normal cumulative distribution function, respectively. Thus, the inverse Mills ratio can be specified as:

$$
\lambda(\bullet)=\varphi(\bullet) /[1-\Phi(\bullet)]
$$

Using Equations (6) and (9), the difference in conditional expectations of agricultural machinery expenditure between the return migrants and non-migrants, or the average treatment effect on the treated (ATET) of rural-urban migration experience on agricultural machinery expenditure, can be obtained as:

$$
\begin{gathered}
A T E T=E\left(Y_{i} \mid M_{i}=1\right)-E\left(Y_{i} \mid M_{i}=0\right) \\
A T E T=\beta+\rho \sigma_{u} \lambda\left(-\vartheta-Z_{i}^{\prime} \delta\right)+\rho \sigma_{u} \lambda\left(\vartheta+Z_{i}^{\prime} \delta\right) \\
A T E T=\beta+\rho \sigma_{u}\left[\lambda\left(-\vartheta-Z_{i}^{\prime} \delta\right)+\lambda\left(\vartheta+Z_{i}^{\prime} \delta\right)\right]
\end{gathered}
$$

There would be no endogeneity of rural-urban migration experience when $\rho=0$ [34], and thus, the OLS method would produce an unbiased and consistent estimation of the impact of rural-urban migration experience on agricultural machinery expenditure. However, the endogeneity exists when $\rho \neq 0$ [34]. The OLS method would result in a biased estimation due to the presence of endogeneity issue arising from the self-selectivity of rural-urban migration experience. In this context, the inverse Mills ratio for the return migrants and non-migrants can be re-written as:

$$
\lambda_{i}= \begin{cases}\lambda\left(-\vartheta-Z_{i}^{\prime} \delta\right), & M_{i}=1 \\ -\lambda\left(\vartheta+Z_{i}^{\prime} \delta\right), & M_{i}=0\end{cases}
$$

Using Equations (6), (9), and (14), the conditional expectation of agricultural machinery expenditure can be specified as:

$$
E\left(Y_{i}\right)=\alpha+\beta M_{i}+X_{i}^{\prime} \gamma+\rho \sigma_{u} \lambda_{i}
$$

It explicitly illustrates that the endogenous treatment-effect model can effectively account for the endogeneity issue of a dummy variable by adding the inverse Mills ratio into the outcome equation. In general, the maximum likelihood estimation method has always been employed to estimate Equation (15).

\subsection{Data}

Data in this study come from a random survey of rice farmers in Guizhou, Hubei, Jiangsu, and Zhejiang provinces in the Yangtze River Basin between October and November 2016. It should be noted that the Yangtze River Basin is the largest rice-growing area in China, where the total sown area and output of rice account for more than $60 \%$ in the country [1]. Guizhou is located in the upper reach, Hubei is located in the middle reach, and both Jiangsu and Zhejiang are located in the lower reach of the Yangtze River Basin. A multistage random sampling method was employed to select the sampled rice farmers. Four rice-producing counties were randomly selected in each province, and in the same way, two township in each county and two villages in each township were then selected. Within each village, about 20 rice farmers were randomly selected based on the household list provided by the village leaders.

A face-to-face questionnaire survey was conducted to collect data among all the randomly selected rice farmers. To ensure the reliability of data, only the household heads were asked to participate in the survey. Information in the survey included the individual characteristics of household heads as well as household characteristics, land management, inputs and output of rice in the largest plots, technical training participation, information sources, and rural-urban migration experience of all farmers. After excluding the farmers 
failing to provide essential information, a total of 1122 farmers remained in this study. Among the sampled farmers were 261 return migrants and 861 non-migrants.

\subsection{Variables and Descriptive Summary}

The variables consist of four types: dependent variable, core independent variable, control variables, and instrumental variable.

1. The dependent variable. In this study, we use agricultural machinery expenditure per hectare (ha) as the dependent variable.

2. Core independent variable. In this study, the core independent variable is farmers' rural-urban migration experience. This is a dummy variable that is equal to one if a farmer had migrated to the urban areas and returned to their hometown when the survey was conducted, and zero when a farmer was a non-migrant.

3. Control variables. In this study, four groups of factors potentially influencing agricultural machinery expenditure are included in the econometric model. The first group includes farmers' individual characteristics, such as gender, age, education, whether they are a village leader, and health self-perception. The second group describes farmers' labor endowment, consisting of the number of household laborers and percentage of off-farm laborers. The third group includes rice planting characteristics, such as whether a land plot is plain, rice farm size, and adoption of direct seeding. The fourth group includes the provincial dummy variables.

4. Instrumental variable. As aforementioned, at least one instrumental variable is needed for estimating the endogenous treatment-effect model. This study employs the percentage of the return migrants in the total sampled farmers in the same village as the instrumental variable of rural-urban migration experience. Many previous studies point out that farmers' rural-urban migration and return to their hometown may be typically and closely associated with collective incentive. In other words, farmers' rural-urban migration would encourage other farmers in the same village to migrate to the urban areas, and more rural-urban migrants return to their hometown would also guide other rural-urban migrants in the same village to return to their hometown $[8,27,37,38]$. Hence, the higher the percentage of the return migrants in a village, the larger the probability of an individual farmer's rural-urban migration experience. In addition, there exists no relationship between the percentage of village-level return migrants and an individual farmer' agricultural production except through rural-urban migration experience.

Table 1 reports the descriptive summary of the main variables and the mean differences in these variables between the return migrants and non-migrants. Overall, there are significant differences in many variables between these two cohorts, indicating the presence of potential endogeneity of their rural-urban migration experience. On average, each farmer spent 201.05 yuan/ha on agricultural machinery in rice production. Male household heads accounted for $93 \%$ among the return migrants and only $90 \%$ among the non-migrants. The average age of household heads among the return migrants was 54.35 years old, and it was 57.80 years old among the non-migrants. The difference in age between two cohorts was significant at the $1 \%$ level. However, the household heads among the return migrants were found to receive an average of 7.64 years of education, 1.33 years more than that among the non-migrants. This is consistent with national statistics showing that more than $80 \%$ of the farmers in China only obtained education in primary or junior middle schools [39]. About $10 \%$ of the sampled farmers were village leaders, and 39\% perceived themselves as healthier than other farmers. In each household, there were about three laborers, and $66.68 \%$ of them were engaged in off-farm work. About $69 \%$ of the land plots were located in the plain area. Moreover, the difference in rice farm size between the return migrants and non-migrants was also significant at the $5 \%$ level. Specifically, rice farm size among the return migrants is averagely 1.70 ha larger than that among the non-migrants. Forty-seven percent of the sampled farmers adopted direct seeding. While the percentage 
of village-level return migrants for the return migrants was $27.64 \%$, it was only $21.93 \%$ for the non-migrants.

Table 1. Descriptive summary of the main variables.

\begin{tabular}{|c|c|c|c|c|}
\hline Variable & Total & Return Migrants & Non-Migrants & Mean Difference \\
\hline Agricultural machinery expenditure (yuan/ha) & $201.05(472.26)$ & $226.10(497.27)$ & $193.45(464.44)$ & 32.64 \\
\hline Male $(1=$ yes, $0=$ no $)$ & $0.90(0.25)$ & $0.93(0.25)$ & $0.90(0.31)$ & $0.04 *$ \\
\hline Age (years) & $57.00(9.68)$ & $54.35(10.66)$ & $57.80(9.22)$ & $-3.45^{* * *}$ \\
\hline Education (years) & $6.62(3.28)$ & $7.64(3.00)$ & $6.31(3.30)$ & $1.33^{* * *}$ \\
\hline Village leader $(1=$ yes, $0=$ no $)$ & $0.10(0.30)$ & $0.11(0.31)$ & $0.10(0.29)$ & 0.02 \\
\hline Health $(1=$ yes, $0=$ no $)$ & $0.39(0.49)$ & $0.38(0.49)$ & $0.40(0.49)$ & -0.02 \\
\hline No. of laborers (persons) & $2.99(1.25)$ & $3.02(1.37)$ & $2.98(1.21)$ & 0.03 \\
\hline Percentage of off-farm laborers & $66.68(29.68)$ & $68.82(29.62)$ & $66.03(29.69)$ & 2.79 \\
\hline Plain $(1=$ yes, $0=$ no $)$ & $0.69(0.46)$ & $0.71(0.45)$ & $0.68(0.47)$ & 0.03 \\
\hline Farm size (ha) & $1.94(10.95)$ & $3.25(12.38)$ & $1.55(10.46)$ & $1.70 * *$ \\
\hline Direct seeding $(1=$ yes, $0=$ no $)$ & $0.47(0.50)$ & $0.46(0.50)$ & $0.47(0.50)$ & -0.02 \\
\hline Percentage of village-level return migrants (\%) & $23.26(10.10)$ & $27.64(10.25)$ & $21.93(9.68)$ & $5.71^{* * *}$ \\
\hline Observations & 1122 & 261 & 861 & \\
\hline
\end{tabular}

Note: ${ }^{* *}, * *$ and $*$ denote significance at the $1 \%, 5 \%$, and $10 \%$ levels, respectively.

\section{Results and Discussion}

\subsection{Main Results}

Table 2 provides the estimation results of rural-urban migration experience's impact on agricultural machinery expenditure in rice production using both the OLS method and endogenous treatment-effect model. First, the estimation results using the endogenous treatment-effect model show that the $\chi^{2}$ statistic of Wald test for independent equations is significant at the $1 \%$ level, implying that there exists a correlation of the error terms between the selection and outcome equations. In other words, the endogeneity issue of rural-urban migration experience exists. The negative correlation coefficient $(\rho)$ means that rural-urban migration experience is an outcome of a negative self-selectivity, which implies that farmers whose agricultural machinery expenditure was lower than the average level had a larger probability of having a rural-urban migration experience. Second, the coefficient of the percentage of village-level return migrants is positive and significant at the $1 \%$ level, implying that there exists a positive relationship between the percentage of village-level return migrants and farmers' rural-urban migration experience. This study further employs the two-stage least-squares method to check whether the instrumental variable is weak. We find that the F statistic is equal to 201.63 and significant at the $1 \%$ level, much larger than its critical value of 10 , which provides evidence that the percentage of village-level return migrants is not a weak instrumental variable. Meanwhile, agricultural machinery expenditure is also regressed on rural-urban migration experience, the percentage of village-level return migrants, and all the other control variables to check the exogeneity of the instrumental variable. The result shows that the coefficient of the percentage of village-level return migrants is equal to 2.81 but not significant. That is, the percentage of village-level return migrants has no partial effect on agricultural machinery expenditure, and thus, it meets the requirement of instrument exogeneity or exclusion restriction. All the aforementioned results demonstrate that employing the endogenous treatment-effect model is necessary and reasonable, and the percentage of village-level return migrants is a valid instrumental variable. 
Table 2. The impact of rural-urban migration experience on agricultural mechanization.

\begin{tabular}{|c|c|c|c|}
\hline \multirow{2}{*}{ Variable } & \multirow{2}{*}{ OLS } & \multicolumn{2}{|c|}{ Endogenous Treatment-Effect Model } \\
\hline & & Selection Equation & Outcome Equation \\
\hline Rural-urban migration experience & $-7.31(25.96)$ & & $561.12^{* * *}(86.01)$ \\
\hline Male & $74.23(54.27)$ & $0.17(0.17)$ & $48.98(59.17)$ \\
\hline Age & $-4.13^{* * *}(1.39)$ & $-0.01^{* *}(0.01)$ & $-1.45(1.73)$ \\
\hline Education & $-6.42(4.03)$ & $0.06^{* * *}(0.02)$ & $-16.77^{* * *}(5.84)$ \\
\hline Village leader & $-2.02(48.14)$ & $-0.12(0.12)$ & $9.91(50.11)$ \\
\hline Health & $20.51(25.54)$ & $-0.18^{* * *}(0.07)$ & $39.55(26.96)$ \\
\hline No. of laborers & $-12.75(12.31)$ & $0.01(0.04)$ & $-21.91(15.07)$ \\
\hline Percentage of off-farm laborers & $0.24(0.44)$ & $0.00(0.00)$ & $-0.15(0.51)$ \\
\hline Plain & $11.55(26.76)$ & $0.16(0.10)$ & $-40.08(34.31)$ \\
\hline $\operatorname{Ln}($ farm size $)$ & $65.06^{* * *}(21.43)$ & $-0.05(0.05)$ & $64.25^{* * *}(22.86)$ \\
\hline Direct seeding & $-117.31^{* * *}(29.41)$ & $0.11(0.08)$ & $-137.95^{* * *}(33.66)$ \\
\hline Provincial dummy variables & Yes & Yes & Yes \\
\hline Percentage of village-level return migrants & & $0.02 * * *(0.00)$ & \\
\hline Constant & $860.24^{* * *}(92.21)$ & $-1.41^{* * *}(0.40)$ & $691.30^{* * *}(120.60)$ \\
\hline Correlation coefficient $(\rho)$ & & $-0.72 * * *(0.10)$ & \\
\hline Wald test for independent equations ( $\chi^{2}$ statistics) & & $21.11^{* * *}$ & \\
\hline Weak instrument test (F statistics) & & $201.63^{* * *}$ & \\
\hline Exogeneity test for instrument & & $2.81(1.78)$ & \\
\hline Observations & 1122 & 1122 & \\
\hline
\end{tabular}

Note: OLS refers to the ordinary least squares method. Figures in parentheses are robust standard errors clustered at the village level. ${ }^{* * *}$, and ${ }^{* *}$ denote significance at the $1 \%$, and $5 \%$ levels, respectively.

In addition to the instrumental variable, farmers' age, education, and health selfperception are found to have a significant relationship with their rural-urban migration experience (Table 2). For example, the coefficient of farmers' age is equal to -0.01 and significant at the $1 \%$ level, demonstrating that farmers' probability of having a ruralurban migration experience decreases as their age increases. The coefficient of farmers' education is positively significant at the $5 \%$ level, which means that there exists a positive relationship between farmers' education and their rural-urban migration experience. As pointed out in previous studies, most rural-urban migrants were young farmers who had received a relatively higher level of formal education [40]. Hence, it accords with the fact that the return migrants are relatively younger and better educated compared with those non-migrants. In addition, the farmers with poorer health self-perception have a smaller probability of having a rural-urban migration experience. This finding is also consistent with the logic of farmers' occupational choice. Rural-urban migrants would be more likely to continue their off-farm work in the urban areas when they consider themselves healthier, but return to their hometown when they have a worse health self-perception.

The most important finding in this study illustrates that rural-urban migration experience significantly increase agricultural machinery expenditure in rice production (Table 2). The estimation results of the outcome equation of the endogenous treatmenteffect model show that the coefficient of rural-urban migration experience is significant at the $1 \%$ level. With other factors held constant, rural-urban migration experience is found to increase agricultural machinery expenditure by 561.12 yuan/ha. In comparison, the estimation results using the OLS method concludes that rural-urban migration experience would not have a significant impact on agricultural machinery expenditure. Such a difference between these two econometric methods may be due to the endogeneity issue of rural-urban migration experience. As aforementioned, rural-urban migration experience is an outcome of negative self-selectivity. Although there exists no significant difference in agricultural machinery expenditure between the return migrants and non-migrants, agricultural machinery expenditure among the return migrants would be largely lower than the current level if they chose not to migrate to the urban areas. In other words, the increase in agricultural machinery expenditure among the return migrants to the current level 
should be mainly attributed to their rural-urban migration experience. Thus, ignoring the endogeneity issue of rural-urban migration experience would result in a biased estimation.

Farmers' education, rice farm size, and adoption of direct seeding also significantly affect their agricultural machinery expenditure (Table 2). The coefficient of farmers' education is equal to -16.77 and significant at the $1 \%$ level. With other factors held constant, if farmers received one more year of formal education, their agricultural machinery expenditure in rice production would accordingly fall by 16.77 yuan/ha. The coefficient of rice farm size is also positively significant at the $1 \%$ level, and thus, a $10 \%$ expansion in rice farm size would result in a 6.425 yuan/ha increase in agricultural machinery expenditure. This finding is consistent with previous studies, which point out that the expansion in farm size can benefit agricultural mechanization [32]. The adoption of direct seeding is found to reduce agricultural machinery expenditure in rice production. Compared with that of the farmers not adopting direct seeding, agricultural machinery expenditure of the farmers adopting direct seeding is 137.95 yuan/ha lower.

\subsection{Robustness Checks}

This study re-defines a new dummy variable of rural-urban migration experience to check the robustness of the aforementioned results. Note that the impact of rural-urban migration experience on agricultural machinery expenditure is subject to the differential extent of the economic and technological conditions between the return migrants and non-migrants. In other words, the larger the difference between two cohorts, the larger the impact of rural-urban migration experience on agricultural machinery expenditure. Meanwhile, the differential extent between two cohorts is influenced by the length of the duration of rural-urban migration experience. We assume that the differential extent between the non-migrants and return migrants with less than two years' rural-urban migration experience is not so large. Thus, this study excludes the farmers with less than two years' rural-urban migration experience from the return migrants. In the robustness check, the dummy variable of a return migrant is equal to one only if the farmer had been a rural-urban migrant for at least two years ( $\geq 2$ years). Table 3 summarizes the results of robustness check using the endogenous treatment-effect model.

Table 3. Results of the robustness checks.

\begin{tabular}{|c|c|c|}
\hline Variable & Selection Equation & Outcome Equation \\
\hline Rural-urban migration experience ( $\geq 2$ years) & & $604.39 * * *(77.62)$ \\
\hline Male & $0.08(0.18)$ & $64.00(58.89)$ \\
\hline Age & $-0.01 * *(0.01)$ & $-1.68(1.65)$ \\
\hline Education & $0.05^{* * *}(0.02)$ & $-14.59 * *(5.76)$ \\
\hline Village leader & $-0.04(0.12)$ & $-6.93(50.32)$ \\
\hline Health & $-0.22 * * *(0.06)$ & $41.16(27.14)$ \\
\hline No. of laborers & $-0.00(0.04)$ & $-20.15(14.75)$ \\
\hline Percentage of off-farm laborers & $0.00(0.00)$ & $-0.16(0.54)$ \\
\hline Plain & $0.24^{* *}(0.10)$ & $-51.19(37.67)$ \\
\hline Ln(farm size) & $-0.05(0.04)$ & $63.91 * * *(23.16)$ \\
\hline Direct seeding & $0.14^{* *}(0.07)$ & $-153.25^{* * *}(34.50)$ \\
\hline Provincial dummy variables & Yes & Yes \\
\hline Percentage of village-level return migrants ( $\geq 2$ years) & $0.02 * * *(0.00)$ & \\
\hline Constant & $-1.25^{* * *}(0.37)$ & $710.11^{* * *}(113.01)$ \\
\hline Correlation coefficient $(\rho)$ & $-0.76^{* * *}(0.09)$ & \\
\hline Wald test for independent equations ( $\chi^{2}$ statistics) & $20.98^{* * *}$ & \\
\hline Weak instrument test (F statistics) & $201.79 * * *$ & \\
\hline Exogeneity test for instrument & $2.63(1.64)$ & \\
\hline Observations & 1122 & \\
\hline
\end{tabular}

Note: Figures in parentheses are robust standard errors clustered at the village level. ${ }^{* * *}$, and ${ }^{* *}$ denote significance at the $1 \%$, and $5 \%$ levels, respectively.

The estimation results of the robustness check is reported in Table 3. The $\chi^{2}$ statistic of the Wald test for independent equations is significant at the $1 \%$ level, which demonstrates the presence of rural-urban migration experience. The correlation coefficient $\rho$ is negative, indicating that there exists a negative self-selectivity bias of rural-urban migration experience. Meanwhile, the coefficient of the percentage of village-level return migrants 
with no less than two years' rural-urban migration experience is positively significant at the $1 \%$ level. The F statistic of the weak instrument test is also significant at the $1 \%$ level, and much larger than its critical value of 10 . Moreover, the coefficient of the instrumental variable for the instrument exogeneity test is not significant. More importantly, the coefficient of rural-urban migration experience is significant at the $1 \%$ level, and thus, rural-urban migration experience would increase agricultural machinery expenditure by 604.39 yuan/ha. In addition to the coefficient of rural-urban migration experience, the coefficients of other variables are overall consistent with the results in Table 2 . Hence, this provides firm evidence for the robustness of findings. It should be noted that this finding to some extent also confirms that a longer duration of rural-urban migration experience would help farmers to accumulate a higher off-farm income, resulting in more expenditure on agricultural machinery. Thus, it provides evidence for the mechanism described in Figure 1a.

\subsection{Heterogeneity Analysis}

To examine the heterogeneity of the impact of rural-urban migration experience on agricultural machinery expenditure, this study divides all the sampled farmers into two groups by farmers' age and rice farm size separately. According to the age, the farmers aged 55 years old and above are divided in a group, and those aged below 55 years old are divided in the other group. Similarly, the farmers whose rice farm size was equal to or larger than $0.67 \mathrm{ha}(=10 \mathrm{mu})$ are divided in a group, and those whose rice farm size was smaller than 0.67 ha are divided in the other group.

Table 4 reports the results of the heterogeneity analysis by farmers' age. It is obvious that rural-urban migration experience exerts a significantly positive impact on agricultural machinery expenditure for both two groups. However, the magnitude of the positive impact differs between these two groups. As for the rice farmers aged 55 years old and above, rural-urban migration experience is found to increase agricultural machinery expenditure by 483.25 yuan/ha. In comparison, the positive impact of rural-urban migration experience on agricultural machinery expenditure is apparently larger among the rice farmers aged below 55 years old. With other factors held constant, rural-urban migration experience would significantly increase agricultural machinery expenditure among the farmers aged below 55 years old by 648.35 yuan/ha. That is, there exists an obvious gap in the positive impact of rural-urban migration experience on agricultural machinery expenditure between these two groups of farmers.

Table 4. Heterogeneity analysis of the impact of rural-urban migration experience on agricultural mechanization by age.

\begin{tabular}{|c|c|c|c|c|}
\hline \multirow{2}{*}{ Variable } & \multicolumn{2}{|c|}{ Age $\geq 55$ Years Old } & \multicolumn{2}{|c|}{ Age $<55$ Years Old } \\
\hline & Selection Equation & Outcome Equation & Selection Equation & Outcome Equation \\
\hline Rural-urban migration experience & & $483.25^{* * *}(77.00)$ & & $648.35^{* * *}(197.92)$ \\
\hline Male & $-0.04(0.23)$ & $48.51(67.93)$ & $0.34(0.28)$ & $32.76(96.77)$ \\
\hline Age & $0.01(0.01)$ & $-5.77^{* *}(2.59)$ & $-0.04^{* * *}(0.01)$ & $2.36(7.46)$ \\
\hline Education & $0.07^{* * *}(0.02)$ & $-17.58 * *(6.95)$ & $0.05 *(0.03)$ & $-10.58(14.63)$ \\
\hline Village leader & $-0.13(0.17)$ & $-41.67(38.12)$ & $0.04(0.19)$ & $53.49(108.64)$ \\
\hline Health & $-0.19 *(0.10)$ & $53.68(33.57)$ & $-0.20 * *(0.10)$ & $34.29(50.19)$ \\
\hline No. of laborers & $-0.01(0.06)$ & $2.01(15.34)$ & $0.05(0.06)$ & $-77.58^{* * *}(29.60)$ \\
\hline Percentage of off-farm laborers & $-0.00(0.00)$ & $0.29(0.64)$ & $0.00(0.00)$ & $-0.83(1.18)$ \\
\hline Plain & $0.02(0.15)$ & $-1.18(32.65)$ & $0.30 *(0.16)$ & $-82.10(66.19)$ \\
\hline Ln(farm size) & $-0.16^{* *}(0.07)$ & $60.41^{* *}(25.81)$ & $0.02(0.06)$ & $63.26 *(35.11)$ \\
\hline Direct seeding & $0.08(0.11)$ & $-94.63 * * *(35.31)$ & $0.15(0.13)$ & $-200.89 * * *(72.01)$ \\
\hline Provincial dummy variables & Yes & Yes & Yes & Yes \\
\hline Percentage of village-level return migrants & $0.02^{* * *}(0.00)$ & & $0.03^{* * *}(0.01)$ & \\
\hline Constant & $-2.82 * * *(0.75)$ & $897.38^{* * *}(198.38)$ & $-0.30(0.78)$ & $627.36(457.97)$ \\
\hline Correlation coefficient $(\rho)$ & $-0.75^{* * *}(0.11)$ & & $-0.72 * *(0.17)$ & \\
\hline Wald test for independent equations ( $\chi^{2}$ statistics) & $13.85^{* * *}$ & & $6.57^{* *}$ & \\
\hline Weak instrument test (F statistics) & $27.08 * * *$ & & $79.54 * *$ & \\
\hline Exogeneity test for instrument & $0.98(1.85)$ & & $5.03(3.20)$ & \\
\hline Observations & 665 & & 457 & \\
\hline
\end{tabular}

Note: Figures in parentheses are robust standard errors clustered at the village level. ${ }^{* * *},{ }^{* *}$, and ${ }^{*}$ denote significance at the $1 \%, 5 \%$, and $10 \%$ levels, respectively. 
Table 5 reports the results of the heterogeneity analysis by farmers' rice farm size. The estimation results of the endogenous treatment-effect model show that the coefficients of rural-urban migration experience in the models for both two groups are positive and significant at the $1 \%$ level. These findings demonstrate that rural-urban migration experience would increase agricultural machinery expenditure by 781.68 yuan/ha among the farmers whose rice farm size was equal to or larger than $0.67 \mathrm{ha}$, and 443.81 yuan/ha among those whose rice farm size was smaller than 0.67 ha. Hence, the difference in the positive impacts is about 338 yuan/ha between these two groups of farmers.

Table 5. Heterogeneity analysis of the impact of rural-urban migration experience on agricultural mechanization by farm size.

\begin{tabular}{|c|c|c|c|c|}
\hline \multirow{2}{*}{ Variable } & \multicolumn{2}{|c|}{ Farm Size $\geq 0.67$ Hectares } & \multicolumn{2}{|c|}{ Farm Size $<0.67$ Hectares } \\
\hline & Selection Equation & Outcome Equation & Selection Equation & Outcome Equation \\
\hline Rural-urban migration experience & & $781.68^{* * *}(118.96)$ & & $443.81^{* * *}(157.09)$ \\
\hline Male & $0.50 *(0.26)$ & $-43.89(110.68)$ & $0.15(0.20)$ & $55.24(66.62)$ \\
\hline Age & $-0.03 * * *(0.01)$ & $1.12(6.06)$ & $-0.01(0.01)$ & $-1.78(1.89)$ \\
\hline Education & $0.12 * * *(0.03)$ & $-41.38^{* *}(19.46)$ & $0.04^{* *}(0.02)$ & $-9.93 *(5.43)$ \\
\hline Village leader & $-0.56(0.37)$ & $267.68(227.56)$ & $0.07(0.14)$ & $-57.21 *(34.01)$ \\
\hline Health & $-0.07(0.15)$ & $53.92(81.99)$ & $-0.25^{* * *}(0.09)$ & $30.93(28.72)$ \\
\hline No. of laborers & $0.04(0.10)$ & $-42.13(61.49)$ & $0.01(0.05)$ & $-14.35(11.96)$ \\
\hline Percentage of off-farm laborers & $0.00(0.00)$ & $-0.09(1.94)$ & $0.00(0.00)$ & $-0.13(0.51)$ \\
\hline Plain & $0.02(0.24)$ & $-87.43(110.47)$ & $0.19 * *(0.10)$ & $-23.87(30.22)$ \\
\hline Ln(farm size) & $-0.12(0.13)$ & $80.54(65.39)$ & $-0.12(0.09)$ & $41.27(29.45)$ \\
\hline Direct seeding & $0.29 *(0.15)$ & $-293.14^{* * *}(100.90)$ & $0.09(0.08)$ & $-86.01 * * *(31.46)$ \\
\hline Provincial dummy variables & Yes & Yes & Yes & Yes \\
\hline Percentage of village-level return migrants & $0.03^{* * *}(0.01)$ & & $0.03 * * *(0.01)$ & \\
\hline Constant & $-1.48^{*}(0.79)$ & $487.89(349.20)$ & $-1.60 * * *(0.53)$ & $622.58 * * *(131.03)$ \\
\hline Correlation coefficient $(\rho)$ & $-0.87^{* * *}(0.06)$ & & $-0.62 * *(0.21)$ & \\
\hline Wald test for independent equations ( $\chi^{2}$ statistics) & $30.90 * * *$ & & $4.93 * *$ & \\
\hline Weak instrument test (F statistics) & $5.59 * *$ & & $190.55^{* * *}$ & \\
\hline Exogeneity test for instrument & $5.95(3.83)$ & & $2.34(1.98)$ & \\
\hline Observations & 257 & & 865 & \\
\hline
\end{tabular}

Notes: Figures in parentheses are robust standard errors clustered at the village level. ${ }^{* * *},{ }^{* *}$, and * denote significance at the $1 \%, 5 \%$, and $10 \%$ levels, respectively.

In general, the farmers with rural-urban migration experience were younger and had a larger rice farm size, and thus, they might have broader horizons, better work capability, and more advanced management philosophy, which would further push them to increase their expected price of labor. Given the larger positive impacts of rural-urban migration experience on agricultural machinery expenditure among the younger and larger-scale farmers, our findings here also confirm the mechanism described in Figure 1b that ruralurban migration would promote the substitute of agricultural machinery for labor through increasing farmers' relative expected price of labor.

\section{Conclusions and Policy Implications}

Since the reform and opening up of the Chinese economy, agricultural mechanization has significantly increased agricultural production efficiency and productivity in China. In the context of promoting rural vitalization on all fronts, agricultural mechanization also has important implications for speeding up the modernization of agriculture and rural areas. In recent years, a large number of rural-urban migrants returned to their hometown and became engaged in agriculture, which would exert a far-reaching impact on the change in agricultural labor force structure and agricultural mechanization. Using the survey data covering 1122 rice farmers in four provinces in the Yangtze River Basin in 2016, this study employs the endogenous treatment-effect model to investigate the impact of rural-urban migration experience on agricultural machinery expenditure among rice farmers by accounting for the potential endogeneity issue. The results show that the return migrants with rural-urban migration experience account for $23.3 \%$ of the total sampled farmers, implying that the return migrants play an increasingly important role in 
agriculture. However, farmers' rural-urban migration experience is an outcome of their self-selective decisions and has an endogeneity issue. After accounting for the endogeneity issue, this study finds that rural-urban migration experience can significantly increase farmers' agricultural machinery expenditure in rice production by 500 to 600 yuan/ha. Ignoring the endogeneity of rural-urban migration experience would greatly under-estimate its positive impact on agricultural machinery expenditure. Meanwhile, the positive impact of rural-urban migration experience would also differ by farmers' age and rice farm size.

This study has several policy implications. First, the government should implement effective policies to assist and support return migrants who have willingness to be engaged in agriculture. In China, small-scale farmers still dominate agricultural production, which seriously limits the improvement of agricultural production efficiency and productivity as well as agricultural mechanization. Return migrants' engagement in agriculture may promote agricultural mechanization due to their advantages in physical capital, human capital, and entrepreneurship [15]. Second, more efforts should be made to support the old farmers to increase their agricultural machinery expenditure. Compared with that among the young farmers, the positive impact of rural-urban migration experience on agricultural machinery expenditure among the old farmers is apparently smaller. This illustrates that the aging of agricultural labor force may be detrimental to developing agricultural mechanization among the return migrants. Third, measures should be taken to enhance the effective coordination of policies promoting agricultural mechanization and appropriately scaled agricultural operation. It should be noted that a larger farm size could not only increase the level of agricultural mechanization, but also reinforce the positive impact of rural-urban migration experience on agricultural machinery expenditure.

Author Contributions: Conceptualization, R.H. and C.Z.; methodology, Y.S. and C.Z.; software, Y.S.; validation, C.Z.; formal analysis, Y.S. and C.Z.; investigation, Y.S.; resources, C.Z.; data curation, C.Z.; writing-original draft preparation, Y.S.; writing-review and editing, C.Z. and R.H.; visualization, Y.S.; supervision, R.H. and C.Z.; project administration, R.H. and C.Z.; funding acquisition, R.H. and C.Z. All authors have read and agreed to the published version of the manuscript.

Funding: This research was funded by the National Natural Science Foundation of China, grant numbers 71661147002 and 71803010, and the Ministry of Science and Technology of China, grant number 2016YFD0201301.

Data Availability Statement: The data presented in this study are available on request from the corresponding author.

Conflicts of Interest: The authors declare no conflict of interest. The funders had no role in the design of the study; in the collection, analyses, or interpretation of data; in the writing of the manuscript, or in the decision to publish the results.

\section{References}

1. National Bureau of Statistics of China. China Statistical Yearbook; China Statistics Press: Beijing, China, 2009. (In Chinese)

2. Hu, Y.; Zhang, Z. Does agricultural machinery service influence technical efficiency in wheat production? Chin. Rural Econ. 2018, 5, 68-83. (In Chinese)

3. Jiao, C.; Dong, L. From "over-densification" to "mechanization": The process, motivation and influence of China's agricultural mechanization revolution (1980 2015). Manag. World 2018, 10, 173-190. (In Chinese)

4. Cao, Y.; Hu, J. Agricultural mechanization in the context of household contract system of land in China based on the survey data in 17 provinces in China. Chin. Rural Econ. 2010, 10, 57-65. (In Chinese)

5. Wang, X.; Yamauchi, F.; Huang, J. Rising wages, mechanization, and the substitution between capital and labor: Evidence from small scale farm system in China. Agric. Econ. 2012, 47, 309-317. [CrossRef]

6. Cai, J.; Tang, Z.; Zhu, Y. The relative price of factors, land resources condition and farmer's demand on agricultural mechanical service outsourcing. Chin. Rural Econ. 2017, 8, 18-28. (In Chinese)

7. Zhao, Y. Causes and consequences of return migration: Recent evidence from China. J. Comp. Econ. 2002, 30, 376-394. [CrossRef]

8. Démurger, S.; Xu, H. Return migrants: The rise of new entrepreneurs in rural China. World Dev. 2011, 39, 1847-1861. [CrossRef]

9. Bryceson, D.F.; Jamal, V. Farewell to Farms: De-Agrarianization and Employment in Africa; Ashgate: Aldershot, UK, 1997.

10. Bryceson, D.F.; Kay, C.; Mooij, J. Disappearing Peasantries? Rural Labour in Africa, Asia and Latin American; Intermediate Technology Publications: Landon, UK, 2000. 
11. Chu, N.Y.; Sung-Ko, L.; Shu-Ki, T. The incidence of surplus labor in rural China: A nonparametric estimation. J. Comp. Econ. 2000, $28,565-580$.

12. Cai, F.; Wang, M. A counterfactual analysis on unlimited surplus labor in rural China. China World Econ. 2010, 16, 51-65. [CrossRef]

13. Yu, L.; Jiang, C. An empirical analysis of the absorption of labor force of the township enterprises in China. Manag. World 2003, 3, 76-82. (In Chinese)

14. Cao, K.H.; Birchenall, J.A. Agricultural productivity, structural change, and economic growth in post-reform China. J. Dev. Econ. 2013, 104, 165-180. [CrossRef]

15. Chen, Q.; Hu, R.; Sun, Y.; Zhang, C. How does rural-urban migration experience affect arable land use? Evidence from 2293 farmers in China. Land 2020, 9, 400. [CrossRef]

16. Zhang, C.; Sun, Y.; Hu, R.; Yang, F.; Shen, X. The impact of rural-urban migration experience on fertilizer use: Evidence from rice production in China. J. Clean. Prod. 2021, 280, 124429. [CrossRef]

17. Shi, Z.; Yang, Y. The effect of rural-urban migration on the capability development of rural labor force and its policy implications Manag. World 2011, 12, 40-54. (In Chinese)

18. Liu, Y.; Hu, W.; Jetté-Nantel, S.; Tian, Z. The influence of labor price change on agricultural machinery usage in Chinese agriculture. Can. J. Agric. Econ. 2014, 62, 219-243. [CrossRef]

19. Li, Q.; Li, D.; Chen, F. Analysis of the effect of plot characteristics on the utilization of agricultural machinery: Based on the rice plots data of South China. Issues Agric. Econ. 2017, 7, 43-52. (In Chinese)

20. Yang, Y.; Li, R.; Wu, M. An analysis of the constraint path of land fragmentation on farmers' purchase of agricultural machinery service. J. Agrotech. Econ. 2018, 10, 17-25. (In Chinese)

21. Wang, X.; Yamauchi, Y.; Huang, J.; Rozelle, S. What constrains mechanization in Chinese agriculture? Role of farm size and fragmentation. China Econ. Rev. 2020, 62, 101221. [CrossRef]

22. Peng, J.; $\mathrm{Wu}, \mathrm{H}$. The influence of land transfer on farmers' agricultural mechanization adoption. China Land Sci. 2019, 33, 73-80. (In Chinese)

23. Fang, S.; Shi, X.; Gao, X. Off-farm employment, investment in agricultural machinery and utilization of agricultural machinery service. J. Nanjing Agric. Univ. Soc. Sci. 2020, 20, 139-149. (In Chinese)

24. $\mathrm{Hu}, \mathrm{X}$.; Mi, Y. The effect and its mechanism of property rights stability on agricultural machinery outsourcing. J. Huazhong Agric. Univ. Soc. Sci. 2020, 3, 63-71. (In Chinese)

25. Zhao, Y. Labor migration and earnings differences: The case of rural China. Econ. Dev. Cult. Chang. 1999, 47, 767-782. [CrossRef]

26. Qian, W.; Wang, D.; Zheng, L. The impact of migration on agricultural restructuring: Evidence from Jiangxi Province in China. J. Rural Stud. 2016, 47, 542-551. [CrossRef]

27. Zhou, G.; Tan, H.; Li, L. Does migration experience promote entrepreneurship in rural China? China Econ. Quart. 2017, 16, 793-814. (In Chinese)

28. Wei, X.; Zhu, H. Return migrants' entrepreneurial decisions in rural China. Asian Popul. Stud. 2020, 16, 61-81. [CrossRef]

29. Wang, S.; Tian, X. The influence of rural labor force aging on agricultural production-An empirical analysis of cultivated land terrain. J. Agrotech. Econ. 2018, 4, 15-26. (In Chinese)

30. Lin, B.; Deng, H. An empirical analysis of the effect of agricultural labor force aging on land use efficiency based on rural fixed point data in Zhejiang Province. Chin. Rural Econ. 2012, 4, 15-25. (In Chinese)

31. Yang, F.; Zhang, Y.; Liu, W. Social network, land scale and productivity-oriented investment of peasant household in agriculture. Reform 2019, 1, 97-108. (In Chinese)

32. Hu, W.; Zhang, J.; Chen, Z. Small farmer and large scale production: Farmland scale and agricultural capital deepening-Taking agricultural machinery operation service as example. J. Agrotech. Econ. 2019, 6, 82-96. (In Chinese)

33. Liu, G.; Song, H. The entrepreneurship of return migrants: Characteristics, causes and its effects-A case analysis of 71 return migrants in four counties in Anhui and Sichuan provinces. Chin. Rural Econ. 2002, 3, 65-71. (In Chinese)

34. Maddala, G.S. Limited Dependent and Qualitative Variables in Econometrics; Cambridge University Press: Cambridge, UK, 1983.

35. Huang, J.; Wang, Y.; Wang, J. Farmers' adaptation to extreme weather events through farm management and its impacts on the mean and risk of rice yield in China. Am. J. Agric. Econ. 2015, 97, 602-617. [CrossRef]

36. Peng, W.; Huang, Z. Can cooperatives help to increase farmers' income? - Analysis based on endogenous switching regression model and cooperatives' service functionality. J. Northweat AEF Univ. Soc. Sci. 2017, 17, 57-66. (In Chinese)

37. Mendola, M. Migration and technological change in rural households: Complements or substitutes? J. Dev. Econ. 2008, 85, 150-175. [CrossRef]

38. Tshikala, S.K.; Kostandini, G.; Fonsah, E.G. The impact of migration, remittances and public transfers on technology adoption: The case of cereal producers in rural Kenya. J. Agric. Econ. 2019, 70, 316-331. [CrossRef]

39. National Bureau of Statistics of China. Available online: http://www.stats.gov.cn/tjsj/pcsj/nypc/nypc3/d3cqgnypchzsj.pdf (accessed on 31 July 2021).

40. Guo, L.; Chen, H.; Cao, Y. The determinants of industrial transfer and rural migrants' willingness of intra-provincial mobilization in the context of return of labor force-A farmer survey conducted in six provinces in the Central China. Chin. Rural Econ. 2011, 6, 45-53. (In Chinese) 